\title{
How do individuals with diabetes use the accident and emergency department?
}

\author{
Elizabeth C Goyder, Stephen W Goodacre, Johannes L Botha, Gautam G Bodiwala
}

\begin{abstract}
Objective-To determine whether the frequency and pattern of use of the accident and emergency (A\&E) department by individuals with diabetes is different from that of the general population.

Methods-A historical cohort of 696 individuals with diabetes from six randomly selected general practices and a nondiabetic comparison cohort matched on age, sex, and general practice were identified. The use of an urban A\&E department by the two cohorts was compared for number of visits between 1984 and 1996 for injuries, diabetes related and non-diabetes related illness, proportion referred by a general practitioner, proportion arriving by ambulance, and proportion
\end{abstract} admitted.

Results-More visits were made by the diabetic cohort $(1002 v 706, P=0.0001)$; 121 visits were directly related to diabetes, including 52 for hypoglycaemia. The diabetic cohort also had more visits for medical illness unrelated to diabetes (357 $v 231, \mathbf{P}=\mathbf{0 . 0 0 0 1}$ ). The number of visits for injuries was similar $(524 v 475, P=0.3)$. Individuals with diabetes who attended A\&E were not significantly more likely to be referred by a general practitioner (14\% $v 16 \%)$ or admitted $(20 \% v 17 \%)$.

Conclusions-Individuals with diabetes made more frequent visits than the general population to the $A \& E$ department. Since there was no excess of visits for injuries and the proportion requiring admission was similar, the hypothesis that they have a different threshold for attending is not supported.

(F Accid Emerg Med 1997;14:371-374)

\section{Accident and}

Emergency Medicine, York District Hospital, York, UK

S W Goodacre

\section{Accident and} Emergency Services, Leicester Royal Infirmary NHS Trust, Leicester, UK G G Bodiwala

Correspondence to: Dr Elizabeth C Goyder, Department of Public Health and Community Medicine, Edward Ford Building A27, University of Sydney, NSW2006, Australia. diabetic individuals visit $A \& E$ no more often than the non-diabetic population in both the United Kingdom ${ }^{5}$ and the USA. ${ }^{6}$ This means that, after excluding problems directly related to diabetes, they visit the department significantly less often. It is plausible that individuals with diabetes might be more likely to use alternatives to $A \& E$, because of more regular contact with general practice or greater reliance on self care for health problems.

The aim of the present study was therefore to compare the frequency and pattern of use of an inner city $A \& E$ department by a cohort of individuals with diabetes to a matched nondiabetic cohort. Our hypothesis was that the diabetic cohort would have a higher threshold for attendance for problems unrelated to diabetes.

\section{Methods}

A cohort of individuals with diagnosed diabetes was identified from the computerised repeat prescribing data of six general practices. Initially a random sample of 10 practices was identified from all practices in the catchment area of Leicester Royal Infirmary A\&E department, the only $A \& E$ department in the city. Seven practices agreed to be involved in the study, of which one was excluded because it did not have a sufficiently accurate computerised age-sex register for matching purposes. From the remaining six practices, 696 individuals, all over the age of 16 and all receiving repeat prescriptions for insulin, oral hypoglycaemic agents, or diabetes testing equipment, were identified. Each individual was matched with the non-diabetic patient closest in age and of the same sex from the same practice. For each individual date of birth, sex, postcode, and medication on repeat prescriptions were recorded. Postcodes were linked to wards, using a computerised postcode directory, in order to calculate Townsend scores from the 1991 census data. The Townsend score is an indicator of material deprivation which combines four variables: unemployment, car ownership, house ownership, and overcrowding. A higher Townsend score indicates greater deprivation. Since previous work has shown that $\mathrm{A} \& \mathrm{E}$ use is related to age, sex, social class, registration with a general practitioner, ${ }^{7}$ and distance from the department, ${ }^{8}$ the matching was designed to achieve similarity in these characteristics to reduce the possibility that differences would be due to confounding by these variables.

Records of all A\&E visits from November 1984 to June 1996 were extracted by manual searches on the $A \& E$ computerised database which has been in use for recording all new registrations (which will not include follow up 
Table 1 Number of individuals receiving repeat prescriptions (excluding diabetes related preparations)

\begin{tabular}{llll}
\hline & $\begin{array}{l}\text { Diabetic cohort } \\
(n=696)\end{array}$ & $\begin{array}{l}\text { Comparison cohort } \\
(n=696)\end{array}$ & McNemar test \\
\hline $\begin{array}{l}\text { Any repeat prescriptions } \\
\text { Cardiovascular drugs }\end{array}$ & $504(72 \%)$ & $369(53 \%)$ & $\mathrm{P}<0.001$ \\
\hline
\end{tabular}

Table 2 Diabetes related visits

\begin{tabular}{lc}
\hline & Number of visits \\
\hline Hypoglycaemia & 52 \\
Hyperglycaemia/ketoacidosis & 2 \\
Diabetic collapse/coma & 7 \\
Diabetes other/not specified & 60 \\
Total & 121 \\
\hline
\end{tabular}

or clinic visits) since November 1984. To minimise the chance of information bias, the data extractor (SWG) was blinded to the diabetic status of individuals, and a standardised search procedure was employed. Every visit was classified, from the reason given for attendance by the attending doctor on the computerised record, as due to diabetes, to other medical illness, or to injury. Self harm was classified as injury because there was insufficient clinical information to make a confident distinction between accidental injury and self harm. Visits due to diabetes were further classified according to the reason for attending. This classification was done independently by two researchers (SWG and ECG) who achieved $100 \%$ agreement, using previously agreed criteria. Information on whether the patient had been referred by a general practitioner or had arrived by way of a 999 call to the emergency ambulance service, and whether the patient was admitted to hospital, was recorded.

DATA ANALYSIS

The data were analysed using SPSS for Windows ${ }^{9}$ and all significance tests were based on a matched analysis. The proportion of visits arising from general practitioner referral, proportion resulting from a 999 call, and proportion resulting in hospital admission were compared, using the sign test, for all three categories of visit described above. For these comparisons only those pairs where both indi-

Table 3 Number of visits by individuals between November 1984 and fune 1996

\begin{tabular}{llcll}
\hline & & $\begin{array}{c}\text { Diabetic cohort } \\
(n=696)\end{array}$ & $\begin{array}{l}\text { Comparison cohort } \\
(n=696)\end{array}$ & $\begin{array}{l}\text { Wilcoxon signed } \\
\text { rank test }\end{array}$ \\
\hline Diabetes related & 0 & $651(94 \%)$ & - & \\
& 1 & $29(4 \%)$ & - & \\
& $2-10$ & $13(2 \%)$ & - & \\
Other medical & $>10$ & $3(0.4 \%)$ & - & \\
& 0 & $505(73 \%)$ & $574(82 \%)$ & \\
& 1 & $130(19 \%)$ & $89(13 \%)$ & \\
Injuries & $2-10$ & $56(8 \%)$ & $31(4 \%)$ & \\
& $>10$ & $5(1 \%)$ & $2(0.3 \%)$ & \\
& 0 & $425(61 \%)$ & $433(62 \%)$ & \\
& 1 & $157(23 \%)$ & $163(23 \%)$ & \\
Total visits & $2-10$ & $111(16 \%)$ & $98(14 \%)$ & \\
& $>10$ & $3(0.3 \%)$ & $2(0.3 \%)$ & \\
& 0 & $322(46 \%)$ & $385(55 \%)$ & \\
& 1 & $180(26 \%)$ & $165(24 \%)$ & \\
& $2-10$ & $186(27 \%)$ & $143(21 \%)$ & \\
& $>10$ & $8(1 \%)$ & $3(0 \%)$ & $\mathrm{P}=0.0001$ \\
\hline
\end{tabular}

viduals had had at least one visit to the department could be included. Only the first 10 visits to the department by any one individual were included to avoid the proportions calculated being dominated by the few more frequent attenders, when the total number of visits was small.

\section{Results}

Each cohort of 696 individuals included 368 men $(53 \%)$ and 328 women $(47 \%)$. The mean age of both cohorts at the start of the period studied was 53.0 years (range 5 to 83 years). The mean age difference between matched pairs was only 19 days. The matching on general practice resulted in the distribution of postcode areas (and therefore distance from the A\&E department) being similar for the two cohorts. Median Townsend scores were 0.7 and 0.3 for the diabetic and non-diabetic cohorts respectively (sign test: $P=0.04$ ). The range of scores was from -5.3 (least deprived) to 10.9 (most deprived).

The proportion of individuals with repeat drug prescriptions, after excluding diabetes related drugs, are compared in table 1 . The proportion of individuals receiving cardiovascular drugs, the category most commonly prescribed, is also shown.

\section{A\&E ATTENDANCES}

There were 1002 visits recorded for the diabetic cohort and 706 for the comparison cohort. Forty five members of the diabetic cohort made 121 visits for diabetes related conditions and these are summarised in table 2. If the type of metabolic disturbance causing a diabetic emergency was not specified, the visit was classified as "diabetic collapse/coma." Visits for which only "diabetes" was given as a diagnosis, and other reasons directly related to diabetes, such as obtaining prescriptions for insulin, were grouped together as "other/not specified."

The numbers of visits, over the 12 year period, by individual patients are shown in table 3. The Wilcoxon signed rank test compares the number of visits for each matched pair and tests the hypothesis that the pattern of visit frequency is the same for both cohorts. Overall the proportion who had ever attended the $A \& E$ department was also significantly higher for the diabetic cohort (McNemar's test: $P=0.0007$ ). The number of visits for medical illness excluding diabetes was significantly higher in the diabetic group. The number of attendances for injuries was similar in the two groups. Table 4 shows the attendance rates for the two cohorts.

There were only eight individuals with more than 10 visits recorded in the diabetic cohort and three in the non-diabetic cohort. All of these had at least 20 visits, and the data collection system was found to be inconsistent in recording of admissions after the first 20 . Only three diabetic individuals $(0.4 \%)$ had more than 10 visits related to diabetes. 
Table 4 Attendance rates for diabetic and non-diabetic cohorts

\begin{tabular}{|c|c|c|c|c|}
\hline & \multicolumn{2}{|c|}{ Diabetic cohort } & \multicolumn{2}{|c|}{ Comparison cohort } \\
\hline & $\begin{array}{l}\text { Rate per } 100 \\
\text { per year }\end{array}$ & $95 \% \mathrm{CI}$ & $\begin{array}{l}\text { Rate per } 100 \\
\text { per year }\end{array}$ & $95 \% \mathrm{CI}$ \\
\hline $\begin{array}{l}\text { Diabetes } \\
\text { related visits }\end{array}$ & 1.49 & 1.25 to 1.78 & - & - \\
\hline Other medical & 4.40 & 3.96 to 4.88 & 2.84 & 2.50 to 3.24 \\
\hline Injuries & 6.45 & 5.92 to 7.03 & 5.84 & 5.33 to 6.39 \\
\hline Total visits & 12.34 & 11.60 to 13.13 & 8.69 & 8.08 to 9.36 \\
\hline
\end{tabular}

CI, confidence interval.

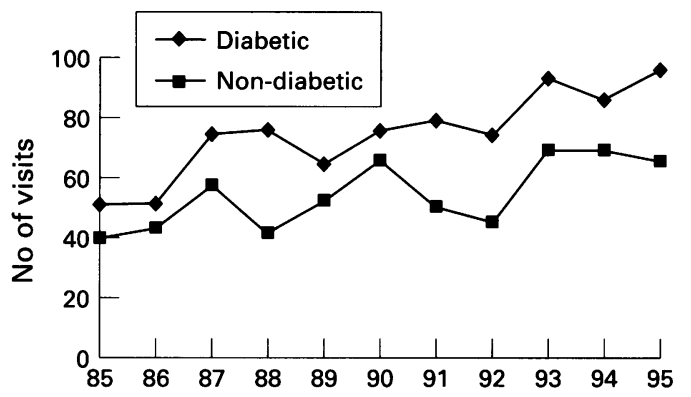

Figure 1 Number of visits annually, 1985-1995.

TIME TRENDS

Trends in the number of visits recorded between 1985 and 1995 are shown in fig 1 . The relative rate of attendance of the diabetic cohort did not change significantly between the first and second half of the period studied. The overall relative rate of attendance for those with diabetes was 1.42 (95\% confidence interval 1.30 to 1.56 ).

SOURCE AND OUTCOME OF ATTENDANCES

The proportions of individuals who had been referred by a general practitioner, who arrived by 999 ambulance, and who were admitted are shown in table 5. Only matched pairs for whom both members had at least one visit are included in this analysis, and the denominator is the total number of visits recorded for these pairs. Similar results to those shown (including only the first 10 visits for an individual) are obtained for the sign tests if recalculated to include all recorded visits.

Individuals with diabetes were no more likely to have been referred to $A \& E$ by a general practitioner or to be admitted from A\&E. They were more likely to have used a 999 ambulance. If visits for injuries only are analysed, it is more likely that an individual

Table 5 Source and outcome for $A \mathcal{E} E$ visits

\begin{tabular}{lccc}
\hline & $\begin{array}{c}\text { Diabetic cohort, } \\
\text { proportion of visits (\%) }\end{array}$ & $\begin{array}{l}\text { Comparison cohort, } \\
\text { proportion of visits (\%) }\end{array}$ & Sign test \\
\hline $\begin{array}{l}\text { Diabetes related visits (n=82 individuals) } \\
\text { GP referral }\end{array}$ & $5 / 82(6 \%)$ & & \\
999 ambulance & $69 / 82(84 \%)$ & - & \\
Admitted & $24 / 82(29 \%)$ & - & \\
Non-diabetes medical visits only $(n=38$ pairs & & \\
GP referral & $14 / 68(21 \%)$ & $13 / 64(20 \%)$ & \\
999 ambulance & $29 / 68(43 \%)$ & $34 / 64(53 \%)$ & $\mathrm{P}=0.6$ \\
Admitted & $32 / 68(47 \%)$ & $29 / 64(45 \%)$ & $\mathrm{P}=0.5$ \\
Injuries related visits only $(n=121$ pairs) & & $\mathrm{P}=0.6$ \\
GP referral & $28 / 238(12 \%)$ & $29 / 224(13 \%)$ & \\
999 ambulance & $58 / 238(24 \%)$ & $34 / 224(15 \%)$ & $\mathrm{P}=0.5$ \\
Admitted & $9 / 238(4 \%)$ & $11 / 224(5 \%)$ & $\mathrm{P}=0.05$ \\
All visits $(n=180$ pairs) & $65 / 457(14 \%)$ & $65 / 399(16 \%)$ & $\mathrm{P}=1$ \\
GP referral & $164 / 457(36 \%)$ & $103 / 399(26 \%)$ & $\mathrm{P}=1$ \\
999 ambulance & $93 / 457(20 \%)$ & $67 / 399(17 \%)$ & $\mathrm{P}=0.02$ \\
Admitted & & & $\mathrm{P}=0.07$ \\
\hline
\end{tabular}

with diabetes will have used an ambulance, while for medical visits no significant difference was found.

\section{Discussion}

We found that individuals with diabetes were more likely to have visited the A\&E department, and attended more often than their matched controls. Where differences are found in the pattern of $A \& E$ use, there are four possible explanations for such differences. First, the difference may be a spurious finding resulting from biases in the data collected. Second, a real difference may be due not to the presence of diabetes but to confounding by a variable associated with both diabetes and $A \& E$ department use (such as deprivation or registration with a general practitioner). If the difference in service use is really due to diabetes, it may reflect either a difference in incidence of health problems or a difference in response to such problems.

\section{POTENTIAL SOURCES OF BIAS}

Studies relying on A\&E records may fail to identify diabetes in those with a presenting problem unrelated to diabetes, and underestimate overall use by this group. The cohort design eliminated this, but some misclassification will occur because identification of the cohorts was retrospective. Some of the members of the diabetic cohort would only have had a diagnosis of diabetes made after the start of the period studied. However, comparison of the first and second halves of the study period suggests that change within the cohorts has not influenced the study conclusions significantly.

A degree of underidentification of attendances because of changes or mistakes in recorded names, addresses, and birth dates is inevitable. However, there is no reason to suggest this source of bias would differ between the two cohorts and so it would not influence relative differences between the cohorts.

\section{POTENTIAL CONFOUNDING VARIABLES}

The design of this study allowed for matching of several known potential confounding variables. Although matched on general practice, individuals with diabetes lived in significantly more deprived wards. This is consistent with the observed association of non-insulin-dependent diabetes and deprivation. ${ }^{10}$ If the analysis is limited to those pairs for whom the diabetic individual was assigned to a Townsend score equal to or less than that of their matched pair (316 pairs), similar differences in visit frequency still are observed, so confounding by deprivation does not explain the differences.

EXPLANATIONS FOR THE DIFFERENCES OBSERVED The significant difference in attendance for medical problems reflects an increased incidence of medical problems (particularly ischaemic heart disease) in the diabetic population. The greater underlying chronic morbidity is confirmed by the greater number of drugs on repeat prescription in this cohort. The pattern of attendance for injuries is not influenced by a diagnosis of diabetes, being very similar in the 
two cohorts. The proportion of visits arising from a general practitioner referral and the proportion resulting in admission are similar, suggesting the casemix of conditions presented is similar.

Our findings do not support the hypothesis that this population, which will make heavy use of other health services, has a different threshold for $A \& E$ attendance. Diabetic individuals are more likely to arrive in $A \& E$ as a result of a 999 ambulance call. This difference is also present when the reason for attendance is an injury and may reflect the fact that individuals with diabetes, or those around them, are more ready to call an ambulance.

\section{IMPLICATIONS}

Previous studies relying on patients to identify themselves as diabetic ${ }^{5}$ or on $\mathrm{A} \& \mathrm{E}$ records $^{6}$ suggest that $A \& E$ use by the diabetic population was lower than expected. This implies that the $A \& E$ department is not an important resource for individuals with diabetes. Our results, showing greater use overall, suggest that previous methods which rely on identifying patients with diabetes when they attend will fail to identify many of those who attend with problems not directly related to diabetes, and therefore will underestimate use of the department by the diabetic population. This has implications for both research and audit, since relying on identifying diabetes within the department may seriously underestimate the numbers attending.

$A \& E$ services have a major role in providing emergency care for patients with diabetes and should therefore be involved in local organisation and coordination of diabetes services.

The presence of chronic disease leads to increased use of primary care and secondary services, but this does not seem to have a significant effect on thresholds for $A \& E$ attendance. Further evidence might come either from a population based study of the management of injuries and medical emergencies in the community, or from more qualitative studies of the way the experience of chronic disease influences use of emergency services.
CONCLUSIONS

In an urban population, the use of an $A \& E$ department was greater by those with diabetes, both for diabetes and other medical reasons, but not for injuries. It is likely that these differences in service use are caused by differences in morbidity. This study provides no evidence that $A \& E$ use by individuals with diabetes is significantly more or less "appropriate" than that of the population registered with general practitioners as a whole, despite more frequent contact with their GPs. It casts doubt over the hypothesis that increased access to primary care can reduce reliance on $A \& E$ departments for individuals with chronic diseases such as diabetes. A\&E departments are likely to continue to have a major role in providing care for individuals with diabetes.

We thank Helen Bottner for organising access to the patient database, Lucy Smith for providing the Townsend scores, and Adam Lowy for statistical advice. We are grateful to the participating general practices without whose involvement the study pating general practices without whose involvement the study Trent Training Fellowship in Health Services Research.

1 Schellevis FG, Van de Lisdonk EH, Van der Velden J, Hoogbergen SHJL, Van Eijk JTM, Van Weel C. Consultations rates and incidence of intercurrent morbidity among patients with chronic disease in general practice. $\mathrm{Br} \mathrm{J}$ Gen Pract 1994;44:259-62.

2 Currie CJ, Williams DRR, Peters JR. Patterns of in and outpatient activity for diabetes: a district survey. Diabetic Med 1996;13:273-80.

3 Potter J, Clarke P, Gale EA, Dave SH, Tattersall RB. Insulin-induced hypoglycamia in an accident and emergency department: the tip of an iceberg? BMJ 1982;285: $1180-2$.

4 Feher M, Grout P, Kennedy A, Elkeles R, Touquet R. Hypoglycaemia in an inner-city accident and emergency department: a twelve month survey. Arch Emerg Med 1989;6:183-8.

5 Holmwood KI, Williams DRR, Roland JM. Use of the accident and emergency department by patients with diabetes. Diabetic Med 1992;9:386-8.

6 Murphy CC, Faulkenberry EH, Rumpel JD, Wheeler EC. The use of a county hospital emergency room by diabetic patients. Diabetes Care 1985;8:48-51.

7 Chambers J, Johnson K. Predicting demand for accident and emergency services. Community Med 1986;8:93-103.

$8 \mathrm{McKee}$ CM, Gleadhill DNS, Watson JD. Accident and emergency attendance rates: variation among patients from different general practices. Br J Gen Pract 1990;40:150-3.

9 SPSS. SPSS for Windows. Cary NY: SPSS, 1993.

10 Meadows P. Variation of diabetes mellitus prevalence in general practice and its relation to deprivation. Diabetic Med 1995;12:696-700. 